inconsistency correlated to the performance of the devices and their ability to float a person where many devices failed. This raised concerns from a consumer perspective and any perception that these devices may provide sufficient flotation to remain on the surface despite the presence of disclaimers.

Despite the inconsistencies in performance, there was sufficient data collected to inform the development of a fit for purpose specification of low buoyancy lifejackets that could be used in high performance applications. This information has since informed the review and redevelopment of the Australian Standard AS4758 Lifejackets and delivered a new class of lifejacket, the Level 25.

Conclusions SLSA are currently trialling prototypes of these Level 25 Lifejackets to assess their possible use in Surf Life Saving activities to reduce injury and death. The final report includes policy recommendations and the necessary implementation plan.

\section{REGIONAL VARIATIONS IN DROWNING DEATH RATES: POPULATION VS. AREA OF NATURAL WATER AS DENOMINATOR}

${ }^{1}$ Isung-Hsueh (Robert) Lu, ${ }^{2}$ Pei-Hsuen Han. ${ }^{1}$ National Cheng Kung University, Taiwan; ${ }^{2}$ Department of Health, Tainan City Government, Taiwan

\subsection{6/injuryprev-2016-042156.1011}

Background Comparing injury death rates by region is a commonly used method to identify regions with higher risk. To correct for exposure, other denominator other than population has been used, such as per miles driven for motor vehicle injuries or per hours flown for injuries in aircraft. We sought to compare regional drowning death rates using population as denominator versus that using area of natural water as denominator.

Methods Drowning deaths in 16 regions in Taitung County Taiwan by for years 2008 through 2013 were collected as numerator in calculating drowning death rates. Mid-year population in 16 regions were used as the first denominator in calculating drowning death rates. Area of natural water (lakes, rivers, streams, beach etc.) in 16 regions were obtained from Water Resource Agency, Ministry of Economic Affair, Taiwan were used as the second denominator in calculating drowning death rates.

Results The rankings of drowning death rates by region according two denominators differed greatly. The drowning death rate using population as denominator in Taitung City was 6.0 per 100,000 population, which ranked $10^{\text {th }}$ among 16 regions in Taitung County. The drowning death rate using area of natural water as denominator in Taitung City was 355 per square km, which ranked the 1 st among 16 regions in Taitung County. We further collected data from fire bureau of Taitung County Government and found a clustering of 8 drowning deaths from 2010 through 2014 in one lake in Taitung City.

Conclusions To identify regions with higher risk of dying from drowning, we recommend of calculating drowning death rate using area of natural water as denominator as a supplement in addition to traditional drowning death rate using population as denominator.

\section{SITUATIONS OF CHILD DROWNING AND PREVENTION BY "MERIT MAKER" TEAM IN SURIN PROVINCE}

${ }^{1}$ Saluckjit Sakulrak, ${ }^{2}$ Sutep Kerdsomnuk, ${ }^{3}$ Stapon Sriwan. ${ }^{1}$ Surin provincial health office; ${ }^{2}$ Sakard School, Noansawan school; ${ }^{3}$ Surin, Thailand

\subsection{6/injuryprev-2016-042156.1012}

Background Drowning is the first cause of death in children who are under 15 years old in Surin province, a province located in the North East of Thailand. Death rate in year 2011, 2012, 2013, 2014, 2015 were 12.94, 11.1, 14.3 ,13.9 respectively per 100,000 children who are below 15 years old . In 2014, a number of drowning children below 15 years between January-October 2014 were 28 cases. There are 32.1 percent of males and 67.86 percent of females. The percentage of drowning children below 2 years old is 17.86 percent. The percentage of drowning children age between 3 to 5 years old, 6 to 9 years old and 9 to 12 years old is 21.3 percent, 28.57 percent and 32.14 percent respectively. The place where drowning occur are community ponds, pond in the field, canel and pond in home and can be calculated as 35.7 percent, 35.7 percent,10.7 percent and10.7 percent respectively. We found that 14.3 percent of children can swim and 85.7 percent of children cannot swim and all of them have no skill in survival swimming. The factor leads to drown is that 46.3 percent of them play in the risk water with friends , 42.86 percent of them was drops in the risk water, 7.14 percent of them was catch the fish and 3.57 percent of them was help their friend who drowning.

Methods The main facter is that most of children do not know how to swim; therefore, they have no skill to help themselves while drowning. In addition, there is few standard pool in local communities. Many schools have no swimming program for students. Also, parents cannot swim and there have many source of water near home and school where children can jump in. According to children behaviour, they like to play in the water with friends during their school break or vacation. The main point we focus on is how children can float in the water and have a right skill to help people or their friends from drowning and have skill on primary resussitatation. Since there are not many standard swimming pool available.

Mobile pool which is given from a supporter is one choice. We adapt survival swimming curriculum for trainer and children. The trainer taught children in easy steps and used easy equipment to help children floating in the water such as plastic bottle. This saves time and is not dangerous while training in mobile pool. We plan best practice school model in local communities. Children who have good skill can train another child.Every district have Trainner.

Results More than 80 percent of students who pass15 hours of survival swimming curriculum can float in the water. The longest hour some children can float is 4 hours. The important technique is they need to learn the right way of how to breath by mouth , how to keep air in lung, make right position and use empty plastic bottle $(1,000 \mathrm{ml})$ when floating in the water. By the knowledge management from team network corporation from Hospital, Health station, School, Local administration and another volunteers which work in Province, district and sub-district, we learn how to be a good teamwork to help children.Our team call 
"MERIT MAKER” (“MERIT MAKER” is stand for Management , Environment, Resuscitation, Information, Trainning (survivalswimming), Media ,Advocacy/policy , Kindergarten , Education and Research ) MERIT MAKER were cover every district in Surin Province

Conclusions Now, we have the best practice in school and set a leader student to be a coach helper and also help friends in survival swimming program. Moreover, we have developed a survival swimming program for 900 trainers from every district, cooperate in school program.In community have prevent on risk resources, have poster and equipment to halp people who wsa drowning. All of this is a concrete success that all school can apply, teach in the process of teamwork and to solve the problem of drowning in Surin. The 7 years of success, between 2010-2015, is our proud. Everyone voluntarily helps children from drowning. The goal is to reduce death rate of drowning lower than 6.5 per 100,000 childrens below 15 years old within 2018. Children can learn survival swimmimg in primary school, can float in water, and know how to help people who drowning.

\section{PROBABILITY OF DROWNING DURING CHILDHOOD IN BANGLADESH}

1,2Abu Talab, ${ }^{3}$ Michael Linnan, 1,2 Aminur Rahman, 1,2 Fazlur Rahman, 1,2 2 aidur Rahman Mashreky. 'Centre for Injury Prevention Research, Bangladesh (CIPRB); ${ }^{2}$ International Drowning Research Centre - Bangladesh (IDRCB); ${ }^{3}$ The Alliance for Safe Children (TA SC)

\subsection{6/injuryprev-2016-042156.1013}

Introduction There are many drowning studies in children that have the potential to allow calculation of the risk or probability of drowning during specific periods of childhood. However, almost none of them include a nationally representative population of children and are large enough to contain enough drowning deaths to have statistical precision in estimating the per-yearof childhood risk of drowning. The Bangladesh Health and Injury Survey (BHIS) allows just such an estimate to be calculated, which puts an actual probability of drowning by year of childhood for children in Bangladesh.

Methods The mortality experience from the child sample from BHIS was examined. A life table was constructed from the child dataset which showed the probability of survival by each year of childhood according to cause of mortality.

Results 169 deaths from drowning occurred in children in BHIS. The multiple decrement life-table analysis which shows age specific probabilities of drowning for children in Bangladesh will be presented at WCDP.

Conclusions The annual risk of dying for children in Bangladesh is already known from the census and other surveys and is high compared with high income countries. The cause-specific mortality risk calculated from the BHIS survey dataset shows that drowning is the largest risk of death from a single cause to children who survive infancy in Bangladesh through their 18th birthday, when they become adults.

Acknowledgements Centre for Injury Prevention and Research Bangladesh (CIPRB)
1014 RESCUE AND EMERGENCY MANAGEMENT OF A WATER RELATED DISASTER: EXPERIENCE FROM BANGLADESH

${ }^{1}$ Abu Sayeed Abdullah, ${ }^{1}$ Shafkat Hossain, ${ }^{1,2}$ Animesh Biswas. ${ }^{1}$ Centre for Injury Prevention and Research, Bangladesh (CIPRB); ${ }^{2}$ Orebro University

\subsection{6/injuryprev-2016-042156.1014}

Background The Padma is one of the largest rivers where thousands of people cross this river every day using boats, launches and ferries. However, the numbers of launce and ferry are insufficient than required. In maximum cases the launches are overloaded with passengers. The authorities do not strictly maintain the rules. A tragic disaster occurred on 22 February 2015 when a cargo vessel hit the launch in the Padma near Paturia launch terminal of Manikganj in Bangladesh and at least 79 people, including 14 children and 28 women, died and over 50 went missing with over 200 passengers on board. The study expresses the practice of rescue process and emergency management services provided in the event.

Methods Qualitative methods including in-depth interviews and a focus group discussion was used to collect data. The daily newspaper reports and related documents were reviewed.

Results On 11:40 am the launch sank in mid-river within 15 minutes after it left the terminal and collided with a cargo vessel. The launch was carrying 200 passengers though its capacity was 140. Around 100 passengers were either rescued or swam around half kilometre to reach the shore. The local people started rescuing passengers immediately after the accident with the help of boats and trawlers from both side. Around 150 members of different government rescue agencies participated in the rescue operation from 12:00 noon to mid night. A rescue vessel reached the spot from Mawa terminal around $11.00 \mathrm{pm}$ after 12 hours to salvage the sunken vessel. After 24 hours of rescue operation 70 bodies were handed over to the family members.

Conclusion The emergency management was inadequate and the authorities in the launches were irresponsible to take appropriate measures to rescue the passengers from drowning. Mass public awareness is essential to follow the rules for safe crossing the river. A national level policy is required for mass rescuing of people during water related disaster.

\section{DESIGN AND EVALUATION OF NOVEL IRISH DROWNING DATA TAXONOMIES FOR A FATALITIES DATABASE}

${ }^{1}$ Aoife Kervick, ${ }^{1}$ Sarah Summerville, ${ }^{2}$ Dani Dix, ${ }^{2}$ Thomas Walters, ${ }^{3}$ Roger Sweeney, ${ }^{1}$ Kiran Sarma. ${ }^{1}$ National University of Ireland, Galway, Ireland; ${ }^{2}$ Royal National Lifeboat Institution, United Kingdom; ${ }^{3}$ rish Water Safety, Ireland

\subsection{6/injuryprev-2016-042156.1015}

Background In the Republic of Ireland (ROI) 135 people drown annually, the majority of which are preventable deaths. Currently, substantial opportunities exist to develop upon the existing methods of managing fatality data in the ROI. The current study thus aimed to develop and evaluate a set of novel drowning data taxonomies, to better record drowning deaths in Irish waters. Improvements to this fatalities taxonomy will enhance accurate incident recording, and benefit subsequent intervention design. 